\title{
Virtual bedside concerts for patients with COVID-19: a trio of perspectives
}

n Cite as: CMAJ 2020 November 2;192:E1370-1. doi: 10.1503/cmaj.201662

CMAJ Podcasts: audio reading at www.cmaj.ca/lookup/doi/10.1503/cmaj.201662/tab-related-content

\section{The cellist}

"This patient with COVID has been sick for several weeks and is not doing well. He's paralyzed and sedated on the ventilator. His son has been having a hard time with this and likes the idea of you playing music for his dad."

I feel the weight of this opportunity and dial into his room.

Silence. The whir of a machine. An occasional rustle. But mostly silence.

Before I begin playing "Sun Up," I ask him to picture the sun rising over a calm lake (Appendix 1, audio file, available at www. cmaj.ca/lookup/doi/10.1503/cmaj.201662/ tab-related-content). I want him to know that this is an entirely personalized concert. Even though he cannot respond, his silence is not emptiness. It's quite the opposite. I lift my bow, inhale, and let the first note sing with warm vibrato. The sound carries from my home to his hospital bed thousands of miles away.

A conductor once told me that rests are the loudest parts of a composition. They must be present for the music to carry weight, to have contrast, to breathe. While playing for this patient, I value that extra space. Every time I take a rest, I am not alone.

Two weeks later, I sign on to a Zoom call to play for the same patient. He is off the ventilator, but still has a surgical airway. Much to my surprise, 16 other squares populate the screen. Family, friends, doctors and nurses surround the patient online. We discover a special moment of congregation and shared humanity, albeit virtual. I delve deeper into my cello than I ever have before, smile and find all the joy and positivity and luck that I have, in being healthy.

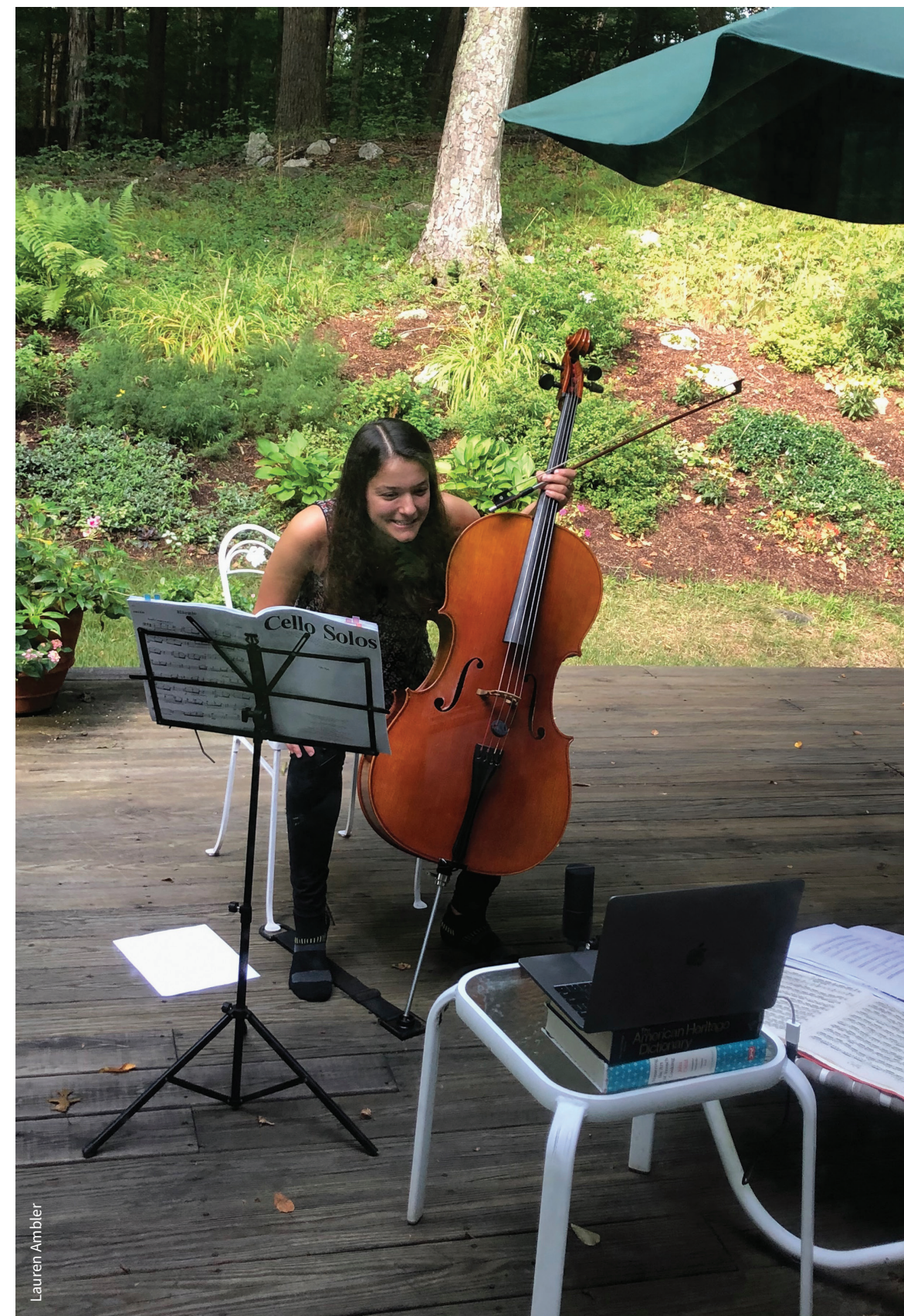

Melanie Ambler prepares to perform for her virtual audience. 
I converse through my music and interact with an entirely present, yet mute audience. This intimate opportunity to play for strangers at their most vulnerable moves me beyond any other performance I've given. I share pieces that are near and dear to my own heart. It's different from playing a recording. We connect through the music. We breathe together.

\section{The nurse}

"Let's review the unit. Which patient might benefit from the gift of live music?"

The choice is difficult; so many patients are ventilated and sedated. Many are not waking up like other patients we have cared for in the past. One has been with us for weeks, ventilated, completely isolated from her family and friends. Can soothing music penetrate her haze of sedation? She must be in there.

I call the cellist.

She smiles, eager to play. "I know you are busy. You can leave the tablet in the patient's room, if you'd like, and I will disconnect when I'm done playing."

Phew - I have so much to do.

I enter the cacophonous room with the cellist ready on the tablet, sit down by the patient's bed and hold her hand. I have held so many hands during the past few months. My mind drifts to all the families that have watched their loved ones take their last breaths via this same tablet, while I hold their hands - an all-toofrequent occurrence for an ICU nurse in the COVID-19 unit. The cellist plays her beautiful instrument and I start to breathe as if this N95 mask is off.

I close my eyes and find solace in the music. The patient's primary nurse listens with me. The cellist may think she is providing only the patient with the gift of live music, but during this time of unimaginable loss and stress, it gives us a glimmer of hope. We are grateful. We stare at the patient, hoping her eyes will open. She needs to get better. She is just like us. This patient is a nurse.

\section{The doctor}

The patient is breathing at 40 a minute. He is slowly waking from seven weeks of intensive care, all on a ventilator, most of it sedated. Now, with a surgical airway and profound weakness, he moves between moments of lucidity and stability, and others of confusion and anxiety. When the cellist, thousands of miles away, plays her first note, his eyes move to the screen. His respiratory rate drops to 20 breaths a minute. He is focused and calm.

Using their cell phones to dial into the concert, the resident team that has been working tirelessly for this patient, and so many others, gathers with pints of ice cream outside the room. They ask me to join them. Inspired by the patient's relaxed breathing, I join the team and breathe for a few minutes myself. As the music plays, a resident spontaneously says, "This job is so hard."

This job is so hard. To see people at their most vulnerable. To witness the joy and sadness that come with the journey of each patient who arrives in the bed in front of us. And now, during the COVID-19 pandemic, to know that we are the only ones who can stand with them during the hardest moments of their lives. There is no way to prepare for the experience of weeping with a family over a video conference as we hold the tablet so they can say goodbye to their loved one, or of sharing in the joy of liberating another person from the ventilator.

To the soundtrack of the cellist, our team explores the pains and delights of being a doctor in this moment. As the music crescendos, it carries our emotions up to the surface. Then a legato, calming phrase arrives and we discover the bandwidth to reflect on what we bear witness to on a daily basis. Through tears, moments of silence, and ice cream, we discuss what has been on our minds, but rarely acknowledged on the front lines. We wonder if we will be okay. Although I do not know the answer to that question, as the cellist begins her last piece, we listen and breathe together. I am hopeful.

\section{Melanie Ambler MS}

Brown University, Providence, RI

\section{Laura Wodecki RN MSN}

Rhode Island Hospital/Lifespan Health

System, Providence, RI

\section{Timothy Amass MD ScM}

Division of Pulmonary Science and Critical Care Medicine, University of Colorado School of Medicine; Department of Veterans Affairs, Eastern Colorado Health Care System, Denver, Colo.

\section{Reference}

1. Weiser B. These are the bedside concerts comforting virus patients. The New York Times 2020 May 3. Available: www.nytimes.com/2020/05/03/nyregion /coronavirus-doctor-musician-rachel-easterwood .html (accessed 2020 July 8).

This article has been peer reviewed.

One of the patients gave consent for this story to be told; the other's daughter gave consent.

The authors have obtained permission to use the audio file "Sun Up," composed in 2008 by cellists Stephen Katz and Derek Snyder, originally written for 6 cellos.

Authors' note: Recently, the New York Times published an article describing how Dr. Rachel Easterwood, an intensive care physician at New York-Presbyterian Allen Hospital, began coordinating virtual bedside concerts for her patients with COVID-19 in mandated isolation. ${ }^{1}$ Inspired by this story, a cellist and aspiring physician, Melanie Ambler, contacted hospital personnel, asking if she could share her music with critically ill patients. Ambler developed muslCforU and received the Rosalind Swenson Enrichment Award from the French American Fulbright Commission to begin a live virtual concert program for hospitals and nursing homes in France, called Petite Pause Musicale. Any hospitals interested in live virtual concerts are welcome to contact her, at petitepausemusicale@gmail.com. 